\title{
Study on Risk Management and Control of Power Transmission and Transformation Project in Power Grid
}

\author{
Xuehua $\mathrm{Zhao}^{1 *}$, Lijuan $\mathrm{Guo}^{2}$, Yan $\mathrm{Li}^{1}$ and Tongyun $\mathrm{Ni}^{2}$ \\ ${ }^{1}$ Economy and Technology Research Institute, State grid Xin Jiang Electric Power Corporation, Wulumuqi 830011, China. \\ ${ }^{2}$ State grid Xin Jiang Electric Power Corporation, Wulumuqi 830011, China.
}

\begin{abstract}
The thesis conducts research on the risk management and control of power grid infrastructure engineering cost, integrates domestic and foreign research on risk management and control related concepts, combines the characteristics of power grid infrastructure engineering, and establishes power grid transmission and transformation through literature analysis, questionnaire survey, entropy weight method and TOPSIS method. Finally, according to the key risk points determined by the empirical analysis, combined with the current status of the power grid infrastructure project cost risk management, a series of targeted measures and suggestions are proposed for the project cost management. The thesis evaluates the impact of the cost risk factors at all stages of the entire life cycle of the power grid infrastructure project, which can provide a useful reference for the establishment and improvement of the power grid transmission and transformation project cost risk management and control system, and has certain practical significance and reference value. Finally, the paper summarizes and prospects the full text. With the gradual deepening of theoretical research and the increasingly perfect engineering cost risk control system, the results of this research will have greater practical value.
\end{abstract}

\section{Introduction}

At present, the macroeconomic situation is still grim, with overcapacity in some industries, the growth rate of electricity sales has slowed, competition in the electricity sales market has intensified, the revenue, profits, and investment capabilities of power companies have been affected. The operation and management of power companies are facing a grim situation. The rigid cost of power companies accounts for a large proportion and grows rapidly. The growth rates of transmission and distribution costs, labor costs, and operation and maintenance costs are all higher than the growth rate of electricity sales. Therefore, strict control of the key areas of power grid infrastructure construction and systematic research on the cost risk of power grid infrastructure construction throughout the life cycle will help to improve the overall risk management and internal control mechanism, establish and improve the long-term risk management and control mechanism, and improve the construction of power grid infrastructure projects. Level, continuously improve the quality of engineering entities, and build a strong smart grid with high quality and efficiency. At present, the cost risk management and control of power grid infrastructure projects focuses on the requirements of cost management objectives and risk identification research, lacking a comprehensive evaluation system and scientific and reasonable evaluation method support, and various units attach different importance to cost risk management and control Considering the issues of cost risk management and control at various stages of the cycle, it is difficult for the construction unit to effectively assess and control the cost risk of the entire power grid infrastructure project. Most of them are still limited to the level of post-event control, and the effectiveness of risk management and control has been greatly improved. space. This article systematically sorts out the cost risk nodes of power grid infrastructure projects in the whole life cycle, and summarizes and refines the targeted prevention and control measures, which is conducive to further strengthening the ability of all parties to deal with the complex and changing power grid infrastructure construction environment, and improve the risk awareness of the actual participants in the cost work. Based on the actual engineering data, analyze the factors of cost risk, the degree of loss, and formulate corresponding prevention and control measures according to relevant system regulations. According to the general system and the in-depth provisions of relevant content, comprehensively sort out and clarify the control subjects of each management level and the responsible subjects of the relevant units. Strengthen horizontal synergy, participate in the whole process of the vertical, and realize the long-term mechanism of power network infrastructure project "full life cycle, full process, full factor, all-round" cost risk management and control.

Therefore, on the basis of a comprehensive and systematic summary of the risk factors of power grid infrastructure projects, the standards for the identification, 
evaluation, and control of power grid infrastructure projects cost risks are put forward, which has a greater role in effectively improving the cost risk management and control capabilities. help. Increasing risk awareness and advancing the normalization of risk identification work is conducive to the realization of risk management and control objectives, and is also essential for improving the economic and social benefits of the project.

\section{Literature review}

Luo Yichao (2015) deeply studied the risk factors during the operation and maintenance of power grid infrastructure projects, and summarized the actual application of risk management and control measures, which is of great significance for identifying the risk factors for the operation and maintenance of power grid infrastructure projects [1]. Liu Weijun (2012) summarized the evaluation and identification methods of broad engineering risk factors, and combed the main development history [2]. Zhang Qilin (2013) uses intelligent digital systems to identify and evaluate the risk factors that occur in the operation and maintenance of power grid infrastructure projects from the perspective of saving engineering costs and improving the ability to quickly handle equipment failures [3]. Chen Jinghui (2010) mainly conducted research on construction projects, summarized the risks of project construction, and proposed corresponding cost risk management and control methods according to the main characteristics of construction projects [4]. Qu Chaoyang (2014) mainly studied the uncertain factors that may have a greater impact in the power grid infrastructure project, and proposed to determine the uncertain factors reasonably on the basis of citing big data technology for data classification and summary analysis [5]. ZHU Mingmin (2012) proposed a risk evaluation model based on Bayesian theory and tree structure theory in order to improve the risk decision-making system during the study of engineering risk, which can give a better interpretation of the transfer and transmission of risks [6] ]. FEND Nan (2013) considers the possibility of risk occurrence in various situations and conducts case studies on the corresponding risk factors. However, he believes that this analysis lacks theoretical basis and is not suitable for popularization and use [7]. Xiong Yongjun (2015) first analyzed the general characteristics of power grid infrastructure projects, and then summarized and summarized the risk management methods applicable to smart grid projects [8]. Ji Shunshang (2010) in the research on the risk management of power grid infrastructure projects, mainly summarized the risk factors of infrastructure expansion projects [9]. Peng Piao (2011) believes that it is necessary to further strengthen the management and control of the risks in the operation and maintenance phase of power grid infrastructure projects, and introduces digital fault detection technology [10]. Haisheng Yang (2012) summarized the risk factors that may occur in the operation and maintenance of power grid infrastructure projects and fault diagnosis, and proposed corresponding identification methods [11].
This study builds a project cost risk management and control system suitable for the characteristics of power grid infrastructure projects [31] [32]. According to the whole process cost management theory, the cost risk management of the power grid infrastructure project of the whole life cycle should be carried out, and all parties involved in the whole process of project management should be combined to carry out all-round and all-angle risk management and control.

\section{Model construction}

\subsection{Entropy weight method}

In the process of evaluation, the determination of indicator weights is a very important task and the basis for constructing a project cost risk indicator system. In this process of determining weights, subjective and objective weighting methods are generally used. In the subjective weighting method, the serial rate method, Delphi method, subjective weighting method and relative comparison method are commonly used; the objective weighting method generally adopts the entropy weighting method, principal component analysis method, mean square error method and coefficient of variation method. The subjective weighting method has a larger subjective factor in the process of determining the weight, which may affect the accuracy of the weight. The objective weighting rule can guarantee the validity and objectivity of the index to the greatest extent. Therefore, this article uses the entropy weight method to determine the weight, and tries to objectively and comprehensively determine the weight of the index. Entropy refers to the degree of chaos in the system. Its concept was first proposed by German physicist Lu Defu in 1850. This concept was first applied in thermodynamics. With the development of entropy theory in various fields, French scholar Claude Shannon first applied the concept of entropy in information theory as an important indicator to measure the uncertainty of information. From then on, the concept of entropy entered information theory Field, and has been more comprehensively developed. In information theory, the calculation formula of entropy is:

$$
e_{i}=-\frac{1}{\ln n} \sum_{j=1}^{n} p_{i j} \ln p_{i j}
$$

In the evaluation index system, the entropy weight method measures the weight of the index according to the variability of the evaluation index. If a certain evaluation index has a large degree of variation, it means that the more complicated information the index has, it also indicates that the index has a greater weight in the evaluation index system; the reverse is also true.

\subsection{TOPSIS method}

In multi-objective decision analysis, TOPSIS method is often used for analysis. The TOPSIS method, also known as "close to ideal solution ranking method" or "dominant disadvantage solution distance method", was first 
proposed in 1981. Among the many new concepts extended by the TOSIS method, the ideal solution and the non-ideal solution are the two most common and basic concepts in the TOPSIS method. The ideal solution is also called the "optimal solution" and the non-ideal solution Also known as the "worst solution". The Euclidean distance between the evaluation object and the two pros and cons is generally used as the basis for judging the pros and cons of the evaluation object.

Among the many comprehensive evaluation methods of multi-objective decision-making with limited schemes, TOPSIS method is a simple and easy-to-operate method that can adapt to multi-objective decision-making problems in various situations. Compared with the single index comparative analysis method, the TOPSIS method can perform a more comprehensive multi-objective evaluation analysis. At the same time, the method has the advantage of being generally applicable to common problems. The TOPSIS evaluation method has a wide range of application fields. It can be applied to both simple and small evaluation objects, and complex evaluation objects with many indicators. It can be used for the overall evaluation of a single-level indicator system or multiplelevel indicators. It is used in the evaluation process of the system; it can be used for longitudinal comparative evaluation of departments within the organization, and also for horizontal comparative evaluation between different organizations.

In the evaluation of cost control risk, combining the entropy weight method and the TOPSIS method has many advantages. First, the entropy weight method has the characteristics of simple process and convenient calculation. Applying the above characteristics to the process of determining the weight of the objective angle of the evaluation index can avoid the shortcomings of insufficient accuracy of the weighting from the subjective angle; second, the calculation using the TOPSIS method The Euclidean distance of the optimal solution and the worst solution is used as the standard of the evaluation index system, which reflects the differentiation from the traditional method of selecting evaluation standards; third, the evaluation results of the TOPSIS method have obvious hierarchy and differentiation, Not only applies to singlelevel indicators, but also applies to the evaluation of multi-level indicators, which can obtain the results of local and overall evaluations.

\section{Index system and result evaluation}

\subsection{Index system construction}

According to the process of power grid infrastructure engineering cost risk identification and following the seven principles established by the grid infrastructure engineering index system, the grid power infrastructure engineering cost risk index system can be constructed, as shown in Table 1. As can be seen from the table, under the first-level indicators of power grid infrastructure project risk, the second-level indicators are selected according to the four main stages of the project, which are the pre-project decision risk, project implementation preparation risk, and project implementation process. Risks, project completion and operational stage risks. In the case of determining the second-level indicators of power grid infrastructure project cost risk, according to the processes of risk identification, decomposing risks, judging whether there are new risks, identifying project risk elements, determining risk events and results, and judging whether a new project risk list is needed, and Sixteen three-level indicators distributed in different stages of the project can be obtained separately. Compared with other unselected risks, the following 16 risks have the characteristics of high probability of occurrence, once the hazard is greater, and the direct impact on the cost is stronger.

Table 1 Cost risk index system for power grid infrastructure construction projects

\begin{tabular}{|c|c|c|}
\hline First-level indicators & Secondary indicators & Third-level indicators \\
\hline \multirow{16}{*}{$\begin{array}{l}\text { Evaluation Index } \\
\text { System of Cost Risk } \\
\text { of Power Grid } \\
\text { Infrastructure } \\
\text { Projects X }\end{array}$} & \multirow{4}{*}{$\begin{array}{l}\text { Risks in the early decision stage of the project } \\
\text { A }\end{array}$} & Planning and design rationality risk $\mathrm{A}_{1}$ \\
\hline & & Compliance risk of feasibility studyA $\mathrm{A}_{2}$ \\
\hline & & Preliminary design riskB ${ }_{1}$ \\
\hline & & Construction drawing design riskB ${ }_{2}$ \\
\hline & \multirow{6}{*}{$\begin{array}{l}\text { Risks at the preparation stage of project } \\
\text { implementation } B\end{array}$} & Bidding management riskB ${ }_{3}$ \\
\hline & & Land acquisition and financing risksB $\mathrm{B}_{4}$ \\
\hline & & Contract template application rate riskB ${ }_{5}$ \\
\hline & & Preparation risk before starting work $\mathrm{B}_{5}$ \\
\hline & & Quality management riskC $\mathrm{C}_{1}$ \\
\hline & & Schedule management risk $\mathrm{C}_{2}$ \\
\hline & \multirow[t]{4}{*}{ Risks during construction $\mathrm{C}$} & Security management riskC $\mathrm{C}_{3}$ \\
\hline & & Visa change riskC $\mathrm{C}_{4}$ \\
\hline & & Progress payment risk $\mathrm{C}_{5}$ \\
\hline & & Process file integrity risk $\mathrm{D}_{1}$ \\
\hline & \multirow[t]{2}{*}{ Project completion and operation stage risks D } & Completion settlement preparation riskD$_{2}$ \\
\hline & & Operation management riskD 3 \\
\hline
\end{tabular}




\subsection{Risk probability and impact assessment}

\subsubsection{Risk probability assessment based on entropy} weight method In the entropy weight method, the information entropy is used to calculate the entropy weight of each indicator according to the degree of change of each indicator, and then the entropy weight is used to modify the weight value of each indicator to obtain the objective weight value. After comparison, combined with the actual situation, this article uses the entropy method to determine the weight of the evaluation index. In 1948, Shannon first proposed the concept of information entropy, and constructed the entropy weight theory after years of research. The entropy weight theory holds that for each sample observation of a specific index, the greater the data difference, the greater the comparison effect of the system on the index, that is, the more information contained in the index, the higher the weight given. This method is mostly used in evaluation problems that require high objectivity. Information is a measure of the degree of order of the system, and entropy is a measure of the degree of disorder of the system. If the system may be in many different states, and the probability of each state occurring is $p_{i}(i=1, \ldots, m)$, Then the entropy of the system is defined as:

$$
e=-\sum_{i=1}^{m} p_{i} \cdot \ln p_{i}
$$

when $p_{i}=1 / \mathrm{m}(i=1, \ldots, m)$, That is, when the probability of various states is the same, The maximum value of entropy is:

$$
e_{\max }=\operatorname{lnm}
$$

The importance of each indicator and the amount of information provided by the indicator are used to determine the final weight of each indicator. For example, there are $\mathrm{m}$ items to be evaluated and $\mathrm{n}$ evaluation indicators to form the original data matrix

$$
A=\left(\begin{array}{ccc}
x_{11} & \cdots & x_{1 n} \\
\vdots & \ddots & \vdots \\
x_{m 1} & \cdots & x_{m n}
\end{array}\right)_{m \times n}
$$

Among them, it is the evaluation value of the ith project under the jth indicator.

After the data matrix is obtained, it is dimensionlessly processed:

For positive indicators (the larger the indicator value, the better)

$$
y_{i j}=\frac{x_{i j}-x_{\min (j)}}{x_{\max (j)}-x_{\min (j)}} \times \alpha+(1-\alpha)
$$

For inverse indicators (the smaller the indicator value, the better)

$$
y_{i j}=\frac{x_{\max (j)}-x_{i j}}{x_{\max (j)}-x_{\min (j)}} \times \alpha+(1-\alpha)
$$

Calculation steps of entropy weight method:

First, make a sample based on the sample observation value $x_{i j}$ of an indicator, and ${ }^{x_{i}}$ belongs to the measure of an indicator, $\left(u_{i 1}, u_{i 2}, \ldots, u_{i j k}\right), 0 \leq u_{i j k} \leq 1$, Then the entropy value $\mathrm{H}$ is

$$
H=-\frac{1}{\log k} \sum_{k=1}^{k} u_{i j k} \log u_{i j k}
$$

When $u_{i j k}=\frac{1}{k}$, uncertainty, That is, the observed value of the index makes the sample have the same degree of membership, that is, the evaluation index does not work, and the contribution value to distinguish the category of the sample is zero. When $u_{i j k}=1$, Then the membership of the remaining samples is zero, At this time, the indicator $u_{i}$ is determined to belong to the category $C_{k}$, and the contribution $u_{i}$ value to the category to distinguish the sample ${ }^{x_{i}}$ is the largest..

$$
V_{0}=1+\frac{1}{\log k} \sum_{k=1}^{k} u_{i j k} \log u_{i j k}
$$

then

$$
W_{i j}=\frac{v_{i j}}{\sum_{j=1}^{m} v_{i j}}
$$

4.2.2 Risk impact assessment based on TOPSIS method The TOPSIS method is a sorting method that approximates the ideal solution. It was first proposed by CLHwang and K. Yoon in 1981. Its basic idea is to express the best and worst cases of the evaluated object based on the existing data., And use the mathematical distance to measure the distance between the evaluated object and the best and worst cases.

In this paper, each index in the cost risk index system of power grid infrastructure construction projects is taken as the evaluation object. Based on the actual engineering data, each risk index is evaluated and ranked to determine the key risk points.

The relative closeness is the best to stay away from the negative ideal solution and close to the positive ideal solution, so the greater the relative closeness, the better the conclusion of the program's effect evaluation. Therefore, the relative closeness is the degree of impact of the power grid construction project cost risk index the size of. Finally, according to the size of the relative closeness, the influence degree ranking of the cost risk index of power grid infrastructure construction is determined. 


\subsection{Risk assessment of power transmission and transformation project cost}

This section uses the actual data of the $220 \mathrm{kV}$ power transmission and transformation project in Suzhou Industrial Park for empirical analysis. The evaluation time is 2 years after it is put into operation. Based on the grid risk evaluation index system for power grid infrastructure projects established above, a set of risk evaluation factors for power grid infrastructure engineering cost is constructed. According to the principle of hierarchy, the risk evaluation indicators are divided into two levels: first level and second level. The first level indicators are:

$$
X=\left\{X_{1}, X_{2}, X_{3}, X_{4}, X_{5}\right\},
$$

The secondary indicators are:

$$
X_{i}=\left\{X_{i 1}, X_{i 2}, \ldots, X_{i j}\right\},
$$

The project cost risk comment set is a collection of evaluation results of all power grid infrastructure project cost risk evaluation indicators. According to the probability of occurrence of risks and the degree of impact, this article divides the evaluation results into 4 levels, each level corresponding to a different score. In this paper, according to the characteristics of power grid construction project cost risk, the risk evaluation level is divided into dangerous, alert, general and good, that is, $\mathrm{C}=(\mathrm{C} 1, \mathrm{C} 2, \mathrm{C} 3$, $\mathrm{C} 4)=($ danger, alert, general, good). The risk losses and risk decisions corresponding to the four risk levels are shown in Table 2.

Table 2 Risk level division and disposal measures

\begin{tabular}{cccc}
\hline $\begin{array}{c}\text { Risk } \\
\text { level }\end{array}$ & $\begin{array}{c}\text { Degree } \\
\text { of risk }\end{array}$ & $\begin{array}{c}\text { frac } \\
\text { tion }\end{array}$ & Risk decision principle \\
\hline 1 & Danger & 90 & $\begin{array}{c}\text { Unacceptable, need to take emergency } \\
\text { measures to eliminate or transfer } \\
\text { Measures must be taken to eliminate or } \\
\text { reduce risks }\end{array}$ \\
3 & Alert & 80 & $\begin{array}{c}\text { Acceptable, but need to strengthen } \\
\text { supervision and management } \\
\text { Can be ignored, not recorded, } \\
\text { monitored and controlled }\end{array}$ \\
\hline
\end{tabular}

According to the actual data of the $220 \mathrm{kV}$ power transmission and transformation project in Suzhou Industrial Park, the evaluation of each cost risk index is shown in the table 3 .

Table 3 Risk rating of power grid infrastructure construction

\begin{tabular}{|c|c|c|c|}
\hline \multirow{6}{*}{$\begin{array}{l}\text { Evaluation } \\
\text { Index } \\
\text { System of } \\
\text { Cost Risk } \\
\text { of Power } \\
\text { Grid } \\
\text { Infrastructu } \\
\text { re Projects }\end{array}$} & $\begin{array}{l}\text { First-level } \\
\text { indicators }\end{array}$ & $\begin{array}{l}\text { Secondary } \\
\text { indicators }\end{array}$ & $\begin{array}{l}\text { Risk } \\
\text { level }\end{array}$ \\
\hline & Risks in the early & $\begin{array}{c}\text { Planning and } \\
\text { design rationality } \\
\text { riskX11 }\end{array}$ & 2 \\
\hline & the project X1 & $\begin{array}{c}\text { Compliance risk } \\
\text { of feasibility } \\
\text { studyX12 }\end{array}$ & 2 \\
\hline & Risks at the & $\begin{array}{c}\text { Preliminary } \\
\text { design riskX21 }\end{array}$ & 1 \\
\hline & $\begin{array}{c}\text { preparation stage } \\
\text { of project }\end{array}$ & $\begin{array}{l}\text { Construction } \\
\text { drawing design } \\
\text { riskX22 }\end{array}$ & 1 \\
\hline & $\begin{array}{l}\text { X2 } \\
\text { Impiementation }\end{array}$ & $\begin{array}{c}\text { Bidding } \\
\text { management } \\
\text { riskX23 }\end{array}$ & 2 \\
\hline
\end{tabular}
cost risk indicators

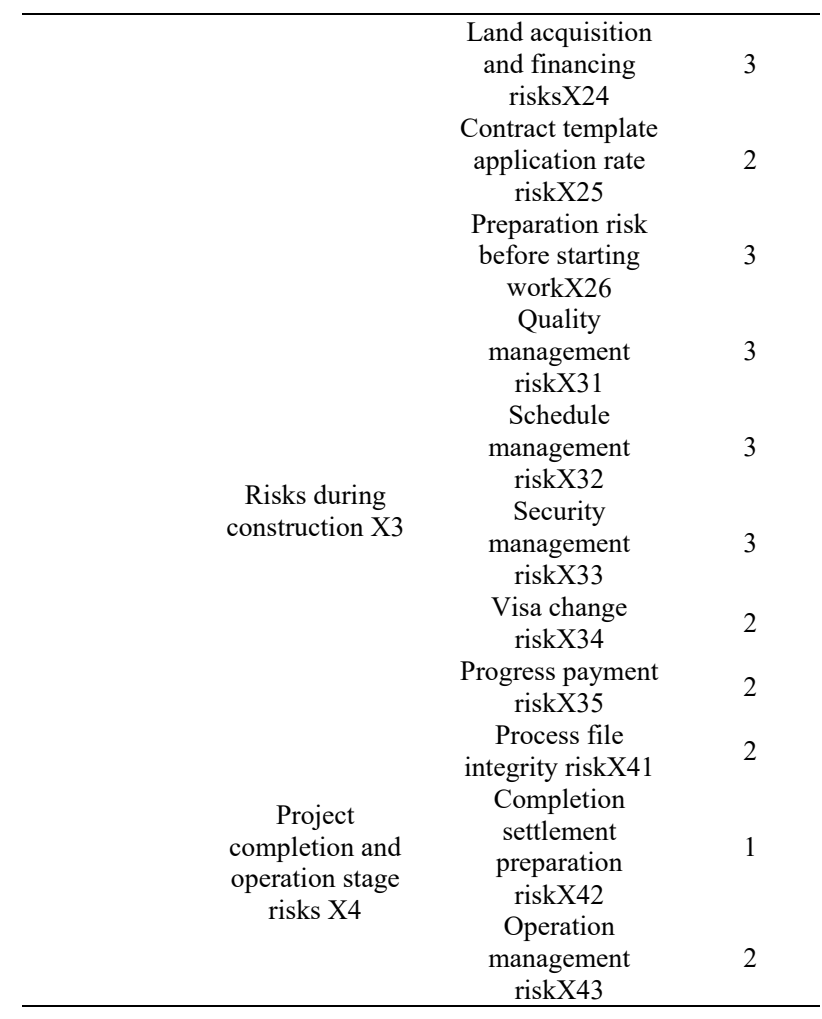

On the basis of the risk comment set, the risk indicators are quantified to determine the degree of membership of the evaluated indicator for each risk level in the risk comment set to form a fuzzy relationship matrix (membership matrix):

$$
A=\left(\begin{array}{ccc}
a_{11} & \ldots & a_{1 n} \\
\vdots & \ddots & \vdots \\
a_{m 1} & \cdots & a_{m n}
\end{array}\right)
$$

Then use the entropy weight method to calculate the weight coefficient of each index. The results are shown in Table 4 and Table 5.

Table 4 Weights of the second-level indicators for the cost risk of power grid infrastructure projects

\begin{tabular}{cc}
\hline Secondary indicators & Weights \\
\hline $\begin{array}{c}\text { Planning and design rationality } \\
\text { riskX11 }\end{array}$ & 0.03 \\
Compliance risk of feasibility & 0.08 \\
studyX12 & 0.15 \\
Preliminary design riskX21 & 0.17 \\
Construction drawing design & riskX22 \\
$\begin{array}{c}\text { Bidding management riskX23 } \\
\text { Land acquisition and financing }\end{array}$ & 0.06 \\
risksX24 & 0.01 \\
Contract template application & rate riskX25 \\
Preparation risk before starting & 0.01 \\
workX26 & 0.05 \\
Quality management riskX31 & 0.01 \\
Schedule management riskX32 & 0.03 \\
Security management riskX33 & 0.02 \\
Visa change riskX34 & 0.06 \\
Progress payment riskX35 & 0.07 \\
Process file integrity riskX41 & 0.13 \\
\hline
\end{tabular}




\begin{tabular}{cc}
\hline $\begin{array}{c}\text { Completion settlement } \\
\text { preparation riskX42 }\end{array}$ & 0.07 \\
Operation management riskX43 & 0.05 \\
\hline
\end{tabular}

Table 5 Weights of first-level indicators for cost risk of power grid infrastructure construction projects

\begin{tabular}{cc}
\hline First-level indicators & Weights \\
\hline $\begin{array}{c}\text { Risks in the early decision } \\
\text { stage of the projectX1 }\end{array}$ & 0.11 \\
$\begin{array}{c}\text { Risks at the preparation stage } \\
\text { of project implementationX2 }\end{array}$ & 0.45 \\
$\begin{array}{c}\text { Risks during constructionX3 } \\
\text { Project completion and } \\
\text { operation stage risksX4 }\end{array}$ & 0.19 \\
\end{tabular}

Finally, according to formulas (9), (10), (11), the TOPSIS method is used to determine the relative closeness of each cost risk index and rank them in order of importance, as shown in Table 6.

Table 6 Evaluation results of power grid infrastructure construction cost risk indicators

\begin{tabular}{ccc}
\hline Risk index & $\begin{array}{c}\text { Relative } \\
\text { progress }\end{array}$ & Rank \\
\hline $\begin{array}{c}\text { Planning and design rationality } \\
\text { riskX11 }\end{array}$ & 0.571 & 7 \\
$\begin{array}{c}\text { Compliance risk of feasibility } \\
\text { studyX12 }\end{array}$ & 0.734 & 4 \\
$\begin{array}{c}\text { Preliminary design riskX21 } \\
\text { Construction drawing design } \\
\text { riskX22 }\end{array}$ & 0.821 & 1 \\
$\begin{array}{c}\text { Bidding management riskX23 } \\
\text { Land acquisition and financing } \\
\text { risks } 24\end{array}$ & 0.813 & 2 \\
Contract template application & 0.616 & 6 \\
rate riskX25 & 0.472 & 10 \\
Preparation risk before starting & 0.382 & 12 \\
$\begin{array}{c}\text { workX26 } \\
\text { Quality management riskX31 }\end{array}$ & 0.556 & 8 \\
Schedule management riskX32 & 0.363 & 13 \\
Security management riskX33 & 0.411 & 11 \\
$\quad \begin{array}{l}\text { Visa change riskX34 } \\
\text { Progress payment riskX35 }\end{array}$ & 0.106 & 16 \\
Process file integrity riskX41 & 0.629 & 5 \\
Completion settlement & 0.483 & 9 \\
preparation riskX42 & 0.795 & 3 \\
Operation management riskX43 & 0.372 & 14 \\
\hline
\end{tabular}

From the final evaluation results, it can be seen that in the entire life cycle of the power grid infrastructure project, according to its cost risk factors in order of influence from the largest to the smallest, the key risk points of the power grid infrastructure project cost are preliminary design risk and construction drawing design. Risk, process file integrity risk, feasibility study compliance risk, and visa change risk. It is roughly consistent with the actual situation, and shows the feasibility and practicability of the risk assessment model of the power grid infrastructure construction cost.

\section{Conclusion}

This paper builds a cost risk index system for power grid infrastructure construction projects. Based on the actual theory of power grid infrastructure engineering and related theories of risk management and control and cost management in the whole process, the paper selects 16 important risk indicators from each stage of the entire life cycle of the power grid infrastructure project through extensive reading of literature and literature analysis methods. The risk index system of power grid infrastructure construction cost has laid a good foundation for the following risk assessment.

The reliability and applicability of the risk assessment model of power grid infrastructure construction cost are verified. The thesis first uses the entropy weight method to determine the weights to reflect the relative importance of each indicator; then, the TOPSIS method is used to calculate the closeness of the weighted standardized data matrix, and the size of the progress is used to reflect the importance of the cost risk index of power grid infrastructure projects degree; finally, through the case of the Suzhou Industrial Park $220 \mathrm{kV}$ transmission and transformation project, an empirical analysis was conducted to test the reliability and applicability of the model. The empirical results show that the key risk points of the power grid infrastructure project cost are preliminary design risk, construction drawing design risk, process file integrity risk, feasibility work compliance risk and visa change risk. The power grid infrastructure project cost risk assessment model is reliable, and applicable. Taking the Suzhou Industrial Park $220 \mathrm{kV}$ power transmission and transformation project as an example, first of all, the project overview is roughly sorted out and summarized to lay a solid foundation for subsequent data processing. Then, in combination with its engineering practice, the power grid infrastructure project cost risk assessment model constructed above is used to make a specific evaluation of the cost risk indicators in the entire life cycle of the power grid infrastructure project and rank them according to the relative closeness of each index to determine the key risk points. Finally, according to the evaluation results and engineering reality, specific measures and suggestions are put forward for project cost risk management and control. On the basis of ensuring the scientificity of the research results, the research results are more practical.

\section{References}

1. Xue Z, Hao J, Chai F, et al. Air Quality Impact of the Coal-Fired Power Plants in the Northern Passageway of the China West-East Power Transmission Project[J]. Journal of the Air \& Waste Management Association, 2005, 55(12):1816-1826.

2. Anonymous. Power Transmission and Distribution Project[J].

3. Guang-Jun Y, Lei Z, Kang S, et al. Discussion on Public Participation in Environmental Impact Assessment of Power Transmission and Transformation Project[J]. North China Electric 
Power, 2016.

4. An X, Yu S, Xuan Z. Environmental Impact on Electromagnetic Radiation of $220 \mathrm{kV}$ Power Transmission and Distribution Project[J]. Environmental Science \& Technology, 2009.

5. Zhu Mingmin, Liu Sanyang Yanu Youlong. Using junction trees for structural learning of Bayesian networks $[\mathrm{J}]$. Journal of Systems Engineering and Electronics ,2012, 23(2):286-292.

6. FEND Nan, WAND H J LI Minqiang. A security risk analysis model for information systems: causal relationships of risk factors and vulnerability propagation analysis[J].Information Sciences, 2015,256(2014):57-73.

7. Yongxuan Xiong, Xin Wu. 500kVResearch on Smart Grid Operation and Maintenance Management Mode [J]. Technology Innovation and Application,2015 (32).

8. Shunshang Ji. REVVATResearch on Risk Management of Power Grid Extension Project [D]. Ocean University of China,2015.

9. Piao Peng, Zhiwei Liao, Digital power grid fault diagnosis based on root cause method [J]. Automation of Electric Power Systems,2015, 35 (17) :61-66.

10. Haisheng Yang, Jianglin Li, Jinye Guo, Research on Uncertainty in Power Grid Fault Diagnosis [J]. Computer Engineering and Design,2012, 33 (5): 2017-2021. 